\title{
Applications of GIS in Business Decision Making: The Case of Egypt
}

\author{
Ahmed Adel Ismael \\ Deanship for Community Service \& Continuing \\ Education, \\ Al Imam Mohammad Ibn Saud Islamic University \\ (IMSIU), \\ Kingdom of Saudi Arabia
}

\author{
Mohamed Sharif Bashir \\ Deanship for Community Service \& Continuing \\ Education, \\ Al Imam Mohammad Ibn Saud Islamic University \\ (IMSIU), \\ Kingdom of Saudi Arabia
}

\begin{abstract}
The main objective of this paper is to design a geospatial database that can help decision makers select the most perfect locations. The present paper also analyzes GIS application with special reference to business administration. The decision makers in business can easily visualize or trace the result that can support the decision making process for choosing the more profitable places or zones areas to open a new branch out of the suggested districts that contain the most of all traffic generators, most of all high-traffic count accessibility, and targeted customers. The present paper also aims to protect decision makers from making a random or subjective decision. The present paper can help to apply the developed GIS to some case studies in the field of business, such as site selection, and evaluate their benefits in supporting business decision making. In this paper, Alexandria, a city in Egypt, is selected to act as a case study, for the design and implementation of a GIS application in distribution strategy for a fast-food restaurant called X.
\end{abstract}

\section{Keywords}

GIS, business administration, spatial database, spatial analysis, geographic information, geospatial database.

\section{INTRODUCTION}

In today's business marketplace, the effective use and flow of information is the key factor to success. Business information parameters, including sales, customer inventory, potential market segmentation, and demographic profile, form the defining factors for all industrial segments, such as retail, real estate, insurance, and pharmaceuticals. Since most of this business information has geographical location, it becomes important to use GIS to analyze them spatially. Business GIS and mapping have evolved into a formidable tool by which the corporate world can use spatial information to manage its business [1]. Especially for companies trying to identify uncovered markets, GIS would support business decisionmaking by adding a spatial component to the decision process. With GIS, businesses make judgments based not only on the attributes of business entities, but on their spatial properties: location, overlaps, proximities, zones of influence, scale, distances. This leads to better-informed decisions.

GIS is an integrated collection of computer software and data used to view and manage information about geographic places, analyze spatial relationships, and model spatial processes. A GIS provides a framework for gathering and organizing spatial data and related information so that it can be displayed and analyzed [2]. GIS can be used as a computer system capable of capturing, storing, analyzing, and displaying geographically referenced information - that is, data identified according to location. Furthermore, GIS helps produce software that enables the geographic mapping of information such as the locations of customers, competitors, suppliers, sales prospects, suppliers, and partners. GIS can be used for site selection, trade area analysis, environmental analysis, sales territory design, and the targeting of marketing [3]. Impacts of GIS on business organizations mean that all types of companies choose GIS to quickly assess real-estate values and market viability. GIS helps business performance in a variety of tasks, including site selection by defining of consumer spending patterns, reallocation of franchise trade areas from the acquisition of new retail outlets, relocation of existing stores based on changing demographic patterns, visualization of market penetration and share of market, mapping of existing customers through address matching, target marketing using lifestyle segmentation statistics, definition of trade areas through drive time analysis, planning for store access by mapping average daily traffic [4]. In this paper the main objective is to design, build, and analyze a geospatial database to help in the use of the place strategy to select the most perfect or the most profitable locations in the city of Alexandria in Egypt to open a new branch for a virtual $\mathrm{X}$ restaurant.

\section{SYSTEM DESCRIPTION}

\subsection{Design Phase}

For the design and analysis, the GIS data model suited for the fast food restaurant applications is proposed to include the following data layers: Alexandria city boundaries layer, Alexandria districts layer, transportation network layer consisting of Alexandria's major and minor streets, commercial-area and trading-center layer including recreational facilities with. cinemas and theatres, restaurants layer, club layer, hotel layer, hospital layer, X restaurant current-branches layer, and $\mathrm{X}$ restaurant current-customers layer. Relevant restaurant site selection criteria must be identified to choose the most suitable location for the restaurant's new branches. The solution for choosing an intelligent criterion could be very complicated. However, the suggested criteria on which the restaurant can decide where to choose branch locations are summarized as follows: each district with a population of at least 15,000 people (by my own subjective selection) where the targeted customers are located, near the traffic generators in districts. 


\subsection{GIS Data Model Design}

The geographical database that is most relevant to fast-food restaurant applications should include multilayer data. The multilayer database includes layers of current restaurant branches. It includes also the locations and sites of customer attractions where many people need fast-food services from restaurant branches during the day. The names and description of the proposed layers and their importance and benefits are explained as follows:

The first data layer, named Police_C.shp, is the base map layer. It represents the boundary of the study area, the city of Alexandria, and the main administrative zones in the city It contains polygon features representing the main police centers in Alexandria. It also includes the main district of the city of Alexandria as shown in figures 1 and 2. These two figures shown as a sample to the work that done to the rest of the other layers. The second data layer, named Road_m.shp, contains line features to show the major and important roads in the city of Alexandria. The third data layer shows the most popular commercial centers of the study area, Alexandria; it is named Center.shp. The layers contains point features; its importance is for answering such queries as where most popular commercial centers in Alexandria are located and the type of their point features. The fourth data layer, named X branches.shp, is the current $\mathrm{X}$ restaurant branches. It contains point features. The importance of this layer is for answering such queries as where $\mathrm{X}$ restaurant branches are located and the type of their point features. The fifth data layer, named Hospital.shp, is the most popular hospitals located in the study area, the city of Alexandria. It contains point features. The importance of this layer is answering such queries as where most popular hospitals in Alexandria are located. The sixth data layer, named Club.shp, is the most popular clubs located in the study area, the city of Alexandria. It contains point features. This layer is important for answering such queries as where most popular clubs in Alexandria are. The seventh data layer, named Cinema.shp, is the most popular cinemas located in the study area, the city of Alexandria. It contains point features important for answering such queries as where most popular cinemas in Alexandria are located and the type of their point features.

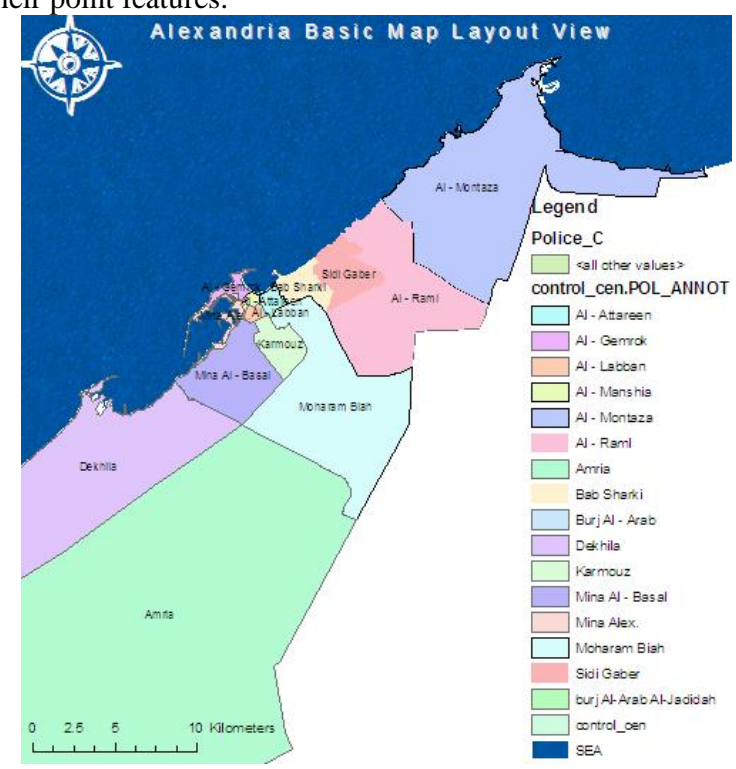

Figure 1: The Base Map Layout Showing the Main Administrative Zones

\begin{tabular}{|c|c|c|c|c|c|}
\hline control_cen.FID & control_cen.AREA & control_cen.PERIMETER & control_cen.P_ & control_cen.P. $\mathrm{ID}$ & control_cen.POL. \\
\hline 0 & 92.96404 & 76.13605 & 2 & & 1 A|. Hontaza \\
\hline 1 & 48.64191 & 39.71988 & 3 & & $2 \mathrm{Al} \cdot \mathrm{Raml}$ \\
\hline 2 & 10.50591 & 17.33088 & 4 & & 3 Sidi Gaber \\
\hline 3 & 5.610255 & 13.9165 & 5 & & 4 Bab Sharki \\
\hline 4 & 2.05692 & 12.06134 & 6 & & 8 Al.Gemrok \\
\hline 5 & 1.8316 & 6.153722 & 7 & & 6 Al. Attareen \\
\hline 6 & 0.73415 & 4.210144 & 8 & & 7 Al. Manshia \\
\hline 7 & 2.527135 & 36.24254 & 9 & & 10 Mina Alex. \\
\hline 8 & 63.02333 & 42.37896 & 10 & & 5 Moharam Biah \\
\hline 9 & 1.081108 & 4.500009 & 11 & & 9 Al. Labban \\
\hline 10 & 7.032354 & 11.768687 & 12 & & 11 Karmouz \\
\hline 11 & 21.30117 & 20.77433 & 13 & & 12 llina Al - Basal \\
\hline 12 & 134.9003 & 76.32018 & 14 & & 13 Dekhila \\
\hline 13 & 1685.216 & 2200.041 & 15 & & 14 Amria \\
\hline 14 & 185.0857 & 72.82092 & 16 & & 15 Burj Al. Arab \\
\hline 15 & 283.0398 & 84.21471 & 17 & & 16 burj Al-Arab Al.Jadidah \\
\hline
\end{tabular}

Figure 2: Police Centers Data Entry Table

The eighth data layer, named Restaurants.shp, is the most popular restaurants located in the study area, the city of Alexandria. It contains point features. The importance of this layer is to answer such queries as where X's most popular restaurants are located and where its competitors are located in Alexandria.

The ninth data layer, named Hotel.shp, is the most popular hotels located in the study area, the city of Alexandria. It contains point features important to answer such queries as where most popular hotels in Alexandria are located.

The last data layer, named Customer.shp, represents the density distribution of $\mathrm{X}$ restaurant customers. It contains point features important for answering such queries as where our customers are located in Alexandria.

\subsection{Data Entry and Editing}

This section describes the phase of building up the geographical database model. Arc-GIS software is used to build and analyze the developed geospatial database model. Arc-GIS is considered a powerful, easy-to-use tool that brings geographic information to the desktop. Arc-GIS has the power to visualize, explore, query, and analyze data spatially. The components of an Arc-GIS session-views, tables, charts, layouts, and scripts - are conveniently stored in one file called a project. The capabilities of ArcGIS include visualizing geographic information, updating information, analyzing information, creating quality information, views of interactive maps that contain one or more theme of GIS, storage of data, tables containing descriptive information about geographic locations, and much more. ArcGIS Desktop is an integrated suite of advanced GIS applications. It includes a series of Windows desktop applications (for example, ArcMap and ArcCatalog) with user interface components. ArcMap is the central application in ArcGIS Desktop for all map-based tasks, including cartography, map analysis, and editing. Arc Map is a comprehensive map-authoring application for ArcGIS Desktop.

The Arc Catalog application helps to organize and manage all your GIS information, such as maps, globes, datasets, models, metadata, and services. It includes tools to browse and find geographic information; record, view, and manage metadata; define, export, and import geodatabase schemas and designs; search for and discover GIS data on local networks and the Web; and administer an ArcGIS server. 


\subsubsection{Geodatabase}

The geodatabase, short for geographic database, is the core geographic information model for organizing GIS data into thematic layers and spatial representations. The geodatabase is a comprehensive series of application logic and tools for accessing and managing GIS data. The geodatabase application logic is accessible in client applications (such as ArcGIS Desktop).

The geodatabase is a GIS and DBMS standards-based physical data store and is implemented on a number of multiuser and personal DBMSs and in XML. The geodatabase was designed as an open, simple geometry storage model. Open to many possible storage mechanisms, including DBMS files and XML implementations, the geodatabase is not tied to a single DBMS vendor [5].

\subsubsection{Geodatabase Storage in Relational Databases}

Geodatabase storage includes both the data dictionary and simple tabular storage of the spatial and attribute data. The GIS database model design explained above can be summarized in table 1 .

Table 1: The Geodatabase Schema Table

\begin{tabular}{|c|c|c|}
\hline $\begin{array}{l}\text { Layer } \\
\text { Name }\end{array}$ & $\begin{array}{l}\text { Layer } \\
\text { Features } \\
\text { Type }\end{array}$ & Layer Description \\
\hline Police_C & $\begin{array}{l}\text { Polygon } \\
\text { Features }\end{array}$ & $\begin{array}{l}\text { This layer represents the main } \\
\text { police centers in Alexandria. It } \\
\text { also includes the main districts } \\
\text { of the city }\end{array}$ \\
\hline Road_m & $\begin{array}{l}\text { Line } \\
\text { Features }\end{array}$ & $\begin{array}{l}\text { Roads connecting and separating } \\
\text { the districts and inner short } \\
\text { streets that connect the ways } \\
\text { between houses and connect } \\
\text { buildings to the subways }\end{array}$ \\
\hline Center & $\begin{array}{l}\text { Point } \\
\text { Features }\end{array}$ & $\begin{array}{l}\text { Locations of most popular } \\
\text { commercial centers in } \\
\text { Alexandria }\end{array}$ \\
\hline $\begin{array}{l}\mathrm{X} \\
\text { Restaurant }\end{array}$ & $\begin{array}{l}\text { Point } \\
\text { Features }\end{array}$ & All current $X$ restaurant branches \\
\hline Hospital & $\begin{array}{l}\text { Point } \\
\text { Features }\end{array}$ & $\begin{array}{l}\text { Locations of most popular } \\
\text { hospitals in Alexandria }\end{array}$ \\
\hline Club & $\begin{array}{l}\text { Point } \\
\text { Features }\end{array}$ & $\begin{array}{l}\text { Locations of most popular clubs } \\
\text { in Alexandria }\end{array}$ \\
\hline Cinema & $\begin{array}{l}\text { Point } \\
\text { Features } \\
\end{array}$ & $\begin{array}{l}\text { Locations of most popular } \\
\text { cinemas in Alexandria }\end{array}$ \\
\hline Hotel & $\begin{array}{l}\text { Point } \\
\text { Features }\end{array}$ & $\begin{array}{l}\text { Locations of most popular hotels } \\
\text { in Alexandria }\end{array}$ \\
\hline Restaurants & $\begin{array}{l}\text { Point } \\
\text { Features }\end{array}$ & $\begin{array}{l}\text { Locations of competitors in } \\
\text { Alexandria }\end{array}$ \\
\hline Customer & $\begin{array}{l}\text { Point } \\
\text { Features }\end{array}$ & $\begin{array}{l}\text { The density distribution of } \mathrm{X} \\
\text { restaurant customers }\end{array}$ \\
\hline
\end{tabular}

\subsubsection{Tables and Relations Diagram}

The second critical part of a database schema is the entity relationships diagram, which shows the relations among the various tables in the database. Relations have a property called cardinality, which describes the type of relation. The possibilities for relationships are one to one, one to many, and many to many. Additionally, relations may have the property of being required (mandatory) or optional. The process of joining tables is based on the value of a field that can be found in both tables. The name of the field does not have to be the same, but the data type has to be the same; one may, for example, join numbers to numbers or strings to strings. Joining tables in Arc Map, one may establish a one-to-one or many-to-one relation between the layer's attribute table and the table containing the joined information.

When data are stored in a table in the database and share a common field with a layer, one may use any of the additional fields to symbolize, label, query, or analyze the layer's features.

\subsubsection{Data Entry}

This phase of building up the geographic database concerns input of the data of various data layers and tables. Arc-GIS is used to design and fill data layers and tables, using data entry tools in Arc-GIS for the various data layers and input to the system. Each layer is first identified as one of three types:

(a) Point Feature Layers: These include cinemas, customers, hotels, restaurants, clubs, hospitals, $\mathrm{X}$ restaurant branches, and centers. Each point feature is selected and inserted in its location in the graphical database in its proper layer. The customer layer is found to include 149 point features. Most of these density distributions for customers are concentrated in the city center (in Sidi Gaber, Al-Montaza, Al-Raml, Mohram Biah, and Bab Sharki); the hotel layer is found to include 6 point features, among which are the most popular hotels in Alexandria. Most of these hotels are concentrated near the main roads and important places; the restaurant layer is found to include 12 point features, among which are the most popular restaurants in Alexandria; the cinema layer is found to include 8 point features, among which are the most popular cinemas in Alexandria, most of htem concentrated in trade centers in the city (in Zahran and Green Plaza, City Center, and San Stefano); the club layer is found to include 7 point features, among which are the most popular clubs in Alexandria; the hospital layer is found to include 11 point features, among which are the most popular hospitals in Alexandria; the $\mathrm{X}$ restaurant layer is found to include 3 point features; the center layer is found to include 6 point features, among which are the most popular malls in Alexandria.

(b) Line Feature Layers: such as Road_M.

(c) Polygon Feature Layer: such as Polic C.

After completing the design phase of the geodatabase model, decision makers have the ability to visualize, explore, query, and analyze data spatially by using modern GISs. Powerful analytical tools as will be shown and discussed in the following chapter.

\subsection{Analysis Phase}

GIS provides sophisticated analysis tools to provide timely information to managers and analysts alike. GIS technology really comes into its own when used to analyze geographic data to look for patterns and trends and to undertake "what if" scenarios.

\subsubsection{Query}

Modern GISs have many powerful analytical tools. They provide simple point-and-click query capabilities. A query builder in Arc-GIS 9.0 was used to answer the various queries to find more suitable locations:

1. Which districts and subdistricts have high population density? 
2. Where are the high-density distribution customers located?

3. Where are the recent $X$ branches?

4. Where are the districts and subdistricts with traffic generators, such as malls, cinema, hotels, and clubs?

5. Where are the districts and subdistricts including high traffic count and accessibility, such as roads where people flow by car and by foot pass?

6. Where are the competitors in districts and subdistricts?

7. Where should $X$ new branches be?

To do this, queries use a query builder by selecting the Police_cen layer, because this layer includes the population for each district and selects a field of population called pop_96 and supposes that the population density is more than 15,000 . One clicks "verify" to confirm that the expression is correct and to specify where these locations are. The results of this query are shown in Figure 3.

Figure 4 shows that all districts have population more than 15,000 except 8 districts as shown in the attributes table of Police C .

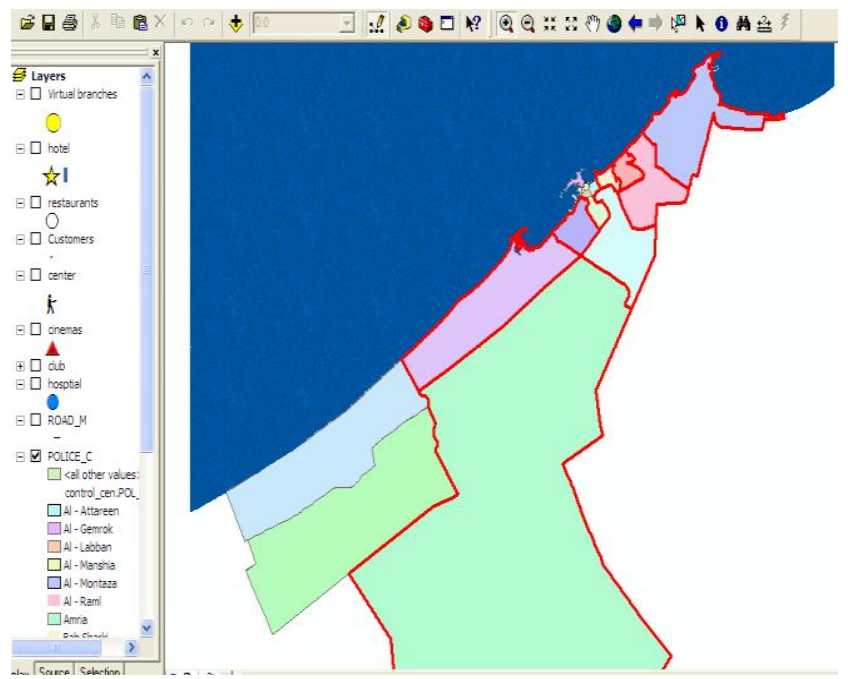

Figure 3: Districts that Include Population more than 15,000 People

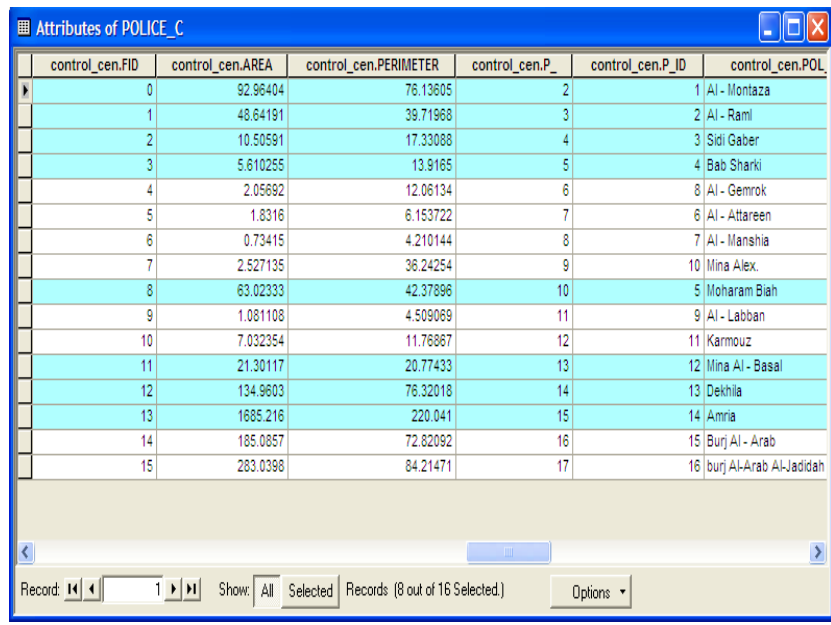

Figure 4 Records that Contain Populations more than 15,000

\subsubsection{Overlay}

The second query aims to show where $\mathrm{X}$ restaurant target customers are located. The query based on slect by loacation tool applies customer layer because this layer includes the location of these customers. The result of this query is shown in Figure 5. The decision maker is able to know where the districts are that contain $\mathrm{X}$ restaurant customers and have populations more than 15,000 . One can apply a third query to show where the recent $\mathrm{X}$ restaurant branches are located by making a query using select by location from the current selection by select $\mathrm{X}$ branches layer because this layer includes the location of the main recent branches. Now the decision maker can know what districts contain the height density distribution for $\mathrm{X}$ restaurant customers who are served by the main recent $X$ restaurant that is included by the same districts containing $X$ restaurant customers, as shown in Figure 6 . By removing from the currently selected features the three districts that are served directly by the $\mathrm{X}$ restaurant branches, the result will include the districts that include the customers far from the main current $\mathrm{X}$ restaurant branches, as shown in Figure 7.

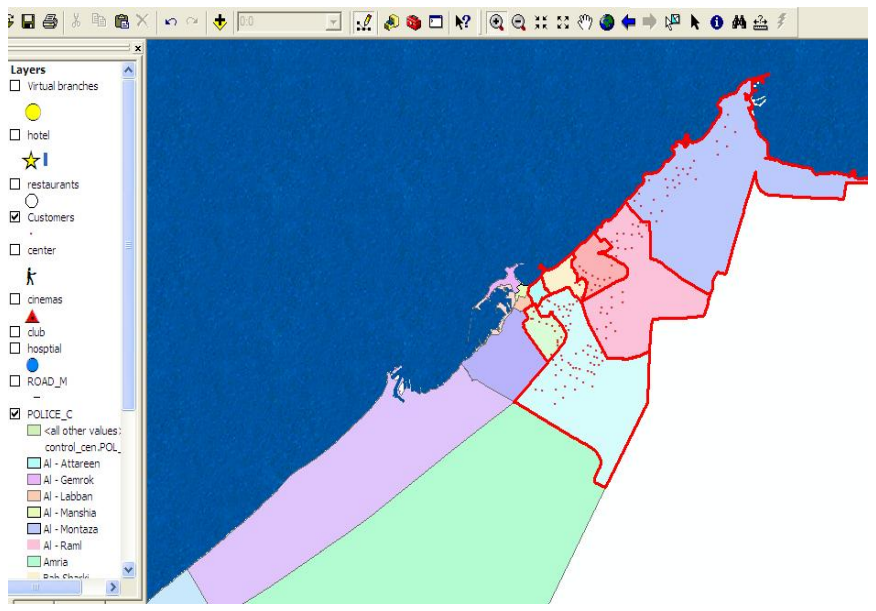

Figure 5: Zones Including High-Density Distribution of Customers

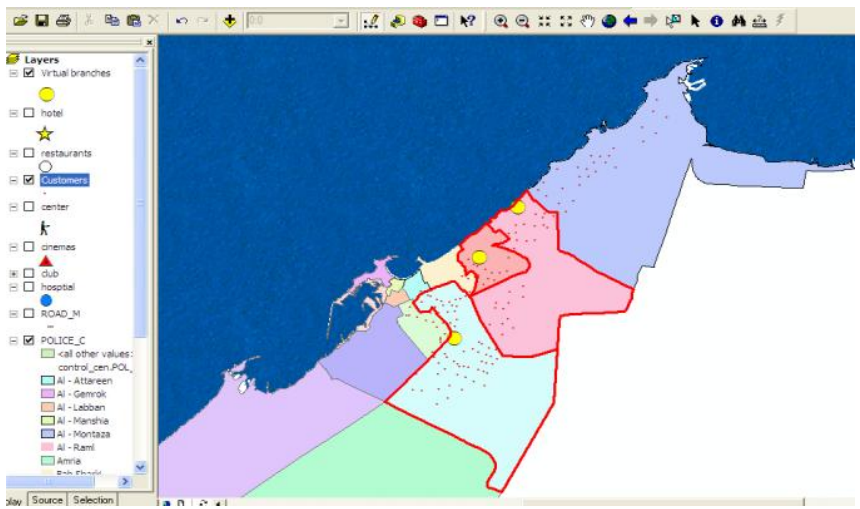

Figure 6: Districts Including X Restaurant Customers and Branches 


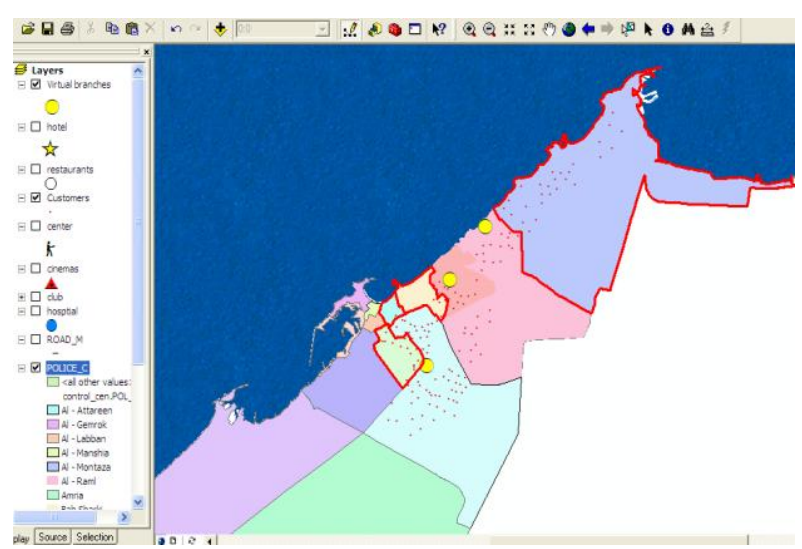

Figure 7: Districts Including Customers Far from Current Branches

\subsubsection{Buffer Zone}

Suppose that each one of the three $\mathrm{X}$ restaurant branches perfectly serve a buffered zone within a distance of $2 \mathrm{~km}$ by the researchers subjective selection, which will be the served zones in the districts that include $\mathrm{X}$ restaurant customers. The detailed explanation appears clearly in Figure 8: to specify the best location to open a new $\mathrm{X}$ restaurant branch through the distribution strategy "Site selection or place strategy" in districts that include many recent customers and buffered zones not covered by $\mathrm{X}$ restaurant branches, many overlay processes may be run to help in this specification. This overlay processes may include all the traffic generators, such as malls, cinemaa, hotels, clubs, and high-traffic-count accessibility such as "People flow by car and by foot pass that intersect," or are contained by the last selected district and subdistrict in Figure 9. A full view to the last figure after adding of traffic generator layers and high-traffic-count accessibility is in Figure 10. As shown in Figure 10, it is clear to the decision maker which of the selected districts and subdistricts are partly within the buffer zone area, when one removes from the currently selected feature the districts that contain recent customers and are not within the buffer zones area; the result will be as shown in Figure 9. Three districts only remain (Al-Montaza, Bab-Sharki, Karmouz), as shown in Figure 10.

\section{RESULTS}

Which of the current three districts completely contain all the traffic generators, such as malls, cinemas, hotels, clubs, and high-traffic-count accessibility, such as "People flow by car and by foot pass"? Figure 11 shows the results.

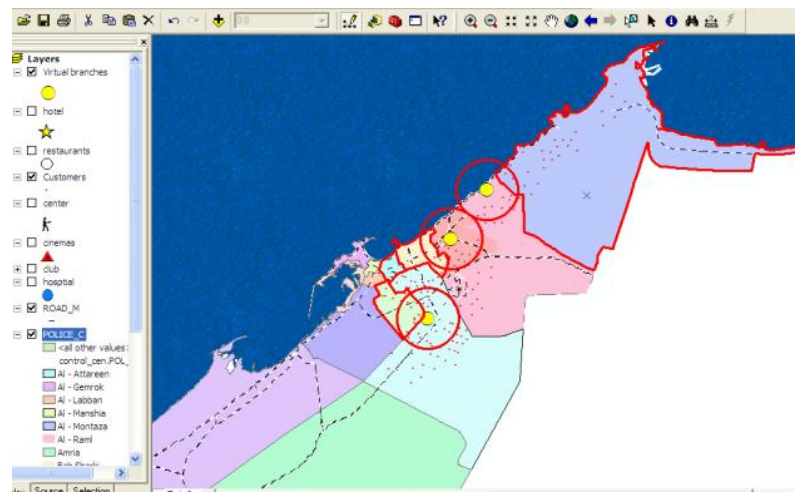

Figure 8: Served Zones in the Districts within a Distance of $2 \mathbf{~ k m}$

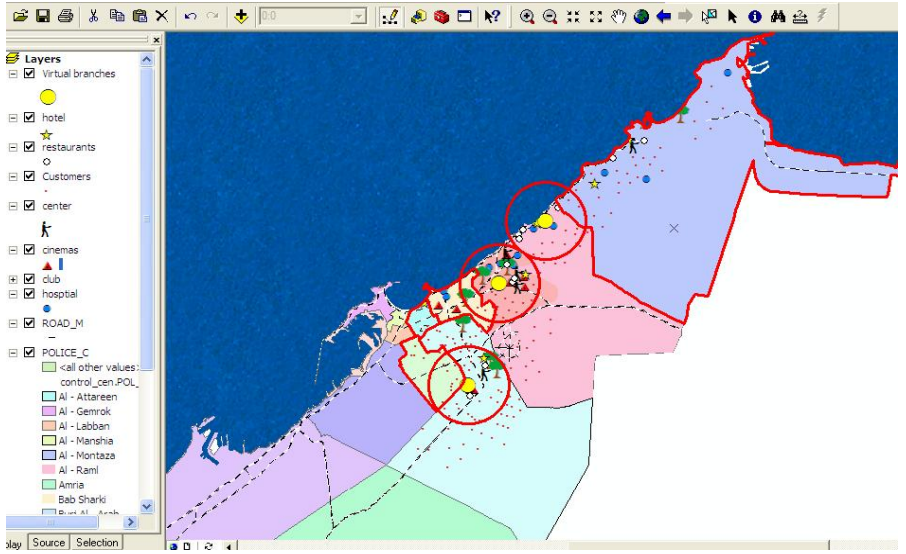

Figure 9: Traffic Generator Layers and High-TrafficCount Accessibility

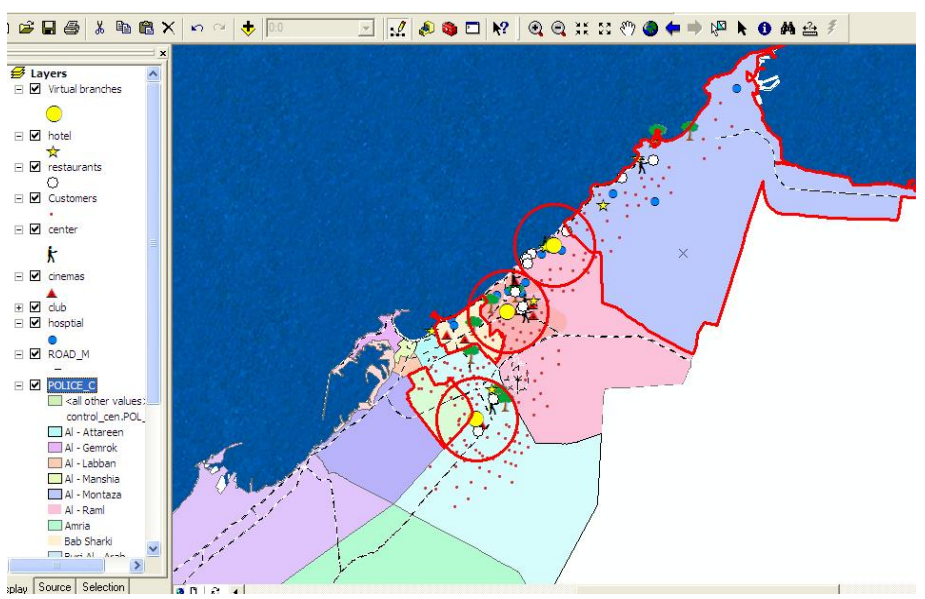

Figure 10: The Eliminated Districts (Al-Attareen)

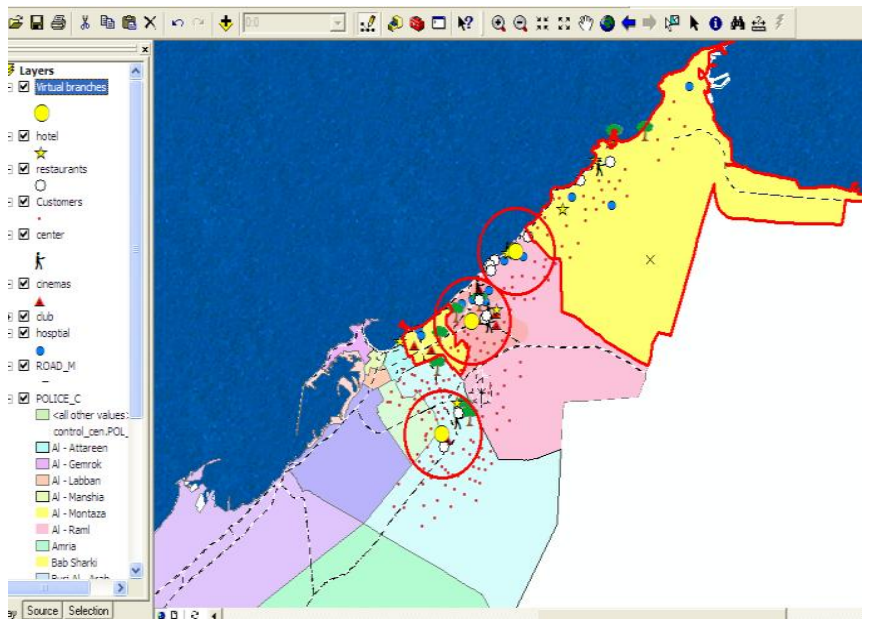

Figure 11: Districts Containing All Traffic Generators and High-Traffic-Count Accessibility

Now by the cooperation and merging between GIS applications and the field of business administration, such as the marketing sector, especially in distribution strategy and specifically "site selection or place strategy," the decision maker can make the right decision by choosing the most profitable place or zone in which to open a new branch of $\mathrm{X}$ restaurant in the two selected districts. 


\section{CONCLUSION}

The paper's main objectives have been to design, build and analyze a geospatial database that can be used in the field of business administration to support business decision making by adding a spatial component to the decision process. With GIS, businesses make judgments based not only on the attributes of business entities, but on their spatial properties as well: location, overlaps, proximities, zones of influence, scale, and distances. This leads to better-informed decisions. $\mathrm{X}$ is a virtual fast-food restaurant deciding where to locate its concessions in a city. The restaurant not only needs attribute information such as its own and competitors' sales and food menu items, but also the distance between its own sites and competitors', proximity to highways, customer locations, and direction of city growth; for these GIS is important in business because most business problems include significant spatial components and GIS enables decision makers to exploit their spatial data resources more effectively and protect them from making a random or subjective decision. From the results, it could be concluded that the decision maker can make the right decision by choosing the most profitable place or zone in which to open a new branch for $\mathrm{X}$ restaurant in the two selected districts. In light of these findings related to GIS study in Alexandria, the researcher recommends that marketing and other commercial sectors organize their efforts to build one geospatial database infrastructure that can be used by all the users and at the same time can be published via the Internet for public use.

\section{REFERENCES}

[1] Carr, T. 2003. Geographic information systems in the public sector. IGI Publishing: USA, 252-270.

[2] Goodchild, M. 1997. What is Geographic Information Science?. Journal of Geographical Information Systems, (2), 31-45.

[3] Goodchild, M.; Yuan, M., and Thomas, J. 2007. Towards a general theory of geographic representation in GIS. Journal of Geographical Information Science. (21), 239260 .

[4] Jack, P. 2005. Geographic information systems in business. Idea Group Publishing: London.

[5] Zhou .G; Kaufmann. P. 2002. .On-Board Geo-Database Management In Future Earth Observing Satellites. Conference (2002). FIEOS/ISPRS. 